\title{
COMPOSITION AND SHORT-TIMESCALE EROSION PATTERNS OF RIVER SEDIMENTS ON DOMINICA
}

HALEY TALBOT-WENDLANDT, Ohio Wesleyan University

Research Advisor: Bart Martin

\section{INTRODUCTION}

Dominica is located in the Caribbean, which is generally an under-studied area of the world for geomorphology (Portenga et al., 2009). There has not been very much prior research conducted in tropical climates because these areas are often less easily accessible than more temperate climates (AlcántaraAyala, 2002). However, it may be more important to study tropical areas than it is to study temperate ones; natural disasters such as volcanic activity and flooding are common in the tropics, and countries located in these areas are often still developing and do not have excess resources readily available to take preventative safety measures or rebuild after a disaster (Alcántara-Ayala, 2002). Because areas with tropical climates receive more rainfall per year than places with temperate climates, various erosive processes can play larger roles in tropical areas than in temperate ones (Vijith et al., 2011). Increased rainfall can lead to more frequent and more intense stormrelated hazards such as landslides (Van Westen, 2016), so it is impossible to simply generalize erosion rates associated with temperate areas and apply those rates to tropical areas (Portenga et al., 2009). Therefore, it is important to determine the background erosion rates in various tropical climates.

Dominica is a young volcanic island, with no known rocks formed more than 7 million years ago (Lindsay et al., 2005). Many of these rocks are ignimbrites, which are easily eroded, especially in a tropical, wet environment such as the Caribbean (Frey, 2016). The exact type of erosion is unknown though, so it would be helpful to use beryllium-7 analyses to determine whether erosion is occurring on horizontal surfaces.
Fallout radionuclide research has already been performed in many other areas of the world, so it will be interesting to analyze this data in the context of a tropical area, and this project will contribute to the continued characterization of tropical processes (Campbell et al., 2015; Hancock et al., 2016). It is especially important to characterize the watersheds and carry out these studies now, while there is relatively little development in most upstream areas.

In order to determine the effects of landslides, storm events, and other erosive processes on different watersheds of Dominica, we collected sediment samples on which we performed compositional, beryllium-7, and lead-210 analyses; and we identified landslides using satellite imagery of the island. I hypothesized that we would be able to differentiate between different watersheds of the island based on the different erosion rates and sediment compositions, with some differences in iron and magnesium ratios between different watersheds and relatively little variation between the fine and coarse sediments from the same watersheds. I expect that fine sediments will be characteristic of more weathered material, since the clay minerals present in Dominica's ignimbrites undergo a weathering sequence (Frey, 2016). I also hypothesized that landslides would tend to occur in the same general areas, and that those areas would be the ones identified as having a high risk of landslides in the World Bank report (Van Westen, 2016). Van Westen (2016) included factors such as slope steepness, elevation, soil type, distance from roads, land use, and underlying geology when evaluating landslide susceptibility in this report. 


\section{METHODS}

\section{Field work}

On Dominica, we sampled twenty watersheds with an area greater than $10 \mathrm{~km}^{2}$ found using ArcMap (Fig. 1). We then sampled each watershed as close as possible to the mouth of the river, while still avoiding tidal influence. At each sample site, we collected active channel sediments from multiple points in the streambed in order to get a more representative sample of the sediments carried by the fluvial system (Gonzalez et al. 2017). For example, we attempted to collect sediment from the channel, point bars, and along the river banks from a longitudinal section of the river whenever possible. We then sieved the mixed sediment to collect only grain sizes of $<63 \mu \mathrm{m}$ and $250-850 \mu \mathrm{m}$. We also took pictures and made written observations of each sample location, including notes on channel width and depth; average channel sediment size, sorting, and rounding; land use; channel type; relative flow velocity; and bank sediment size. We also noted the location of current bridges in addition to old, washed-out bridges still in place along the river.

\section{XRD analysis}

After collecting the samples, we dried them in an oven. We then re-powdered the finer-grained samples with a mortar and pestle as necessary and performed $\mathrm{x}$-ray diffraction analysis on these samples. We ran each sample from $2 \theta=5^{\circ}-85^{\circ}$ at $4^{\circ} / \mathrm{min}$, with the diffractometer set to Bragg-Brentano geometry and $\lambda=1.54056$. We found peaks using a computer program, PDXL.

\section{XRF analysis}

We used a handheld XRF device to analyze the chemistry of the fine-grained and powdered coarsegrained samples. We used the USGS Majors 3 method and ran each coarse-grained sample for 180 seconds and each fine-grained sample for 240 seconds. Although this data was uncalibrated, we were able to compare the ratios of various elements in the different samples.

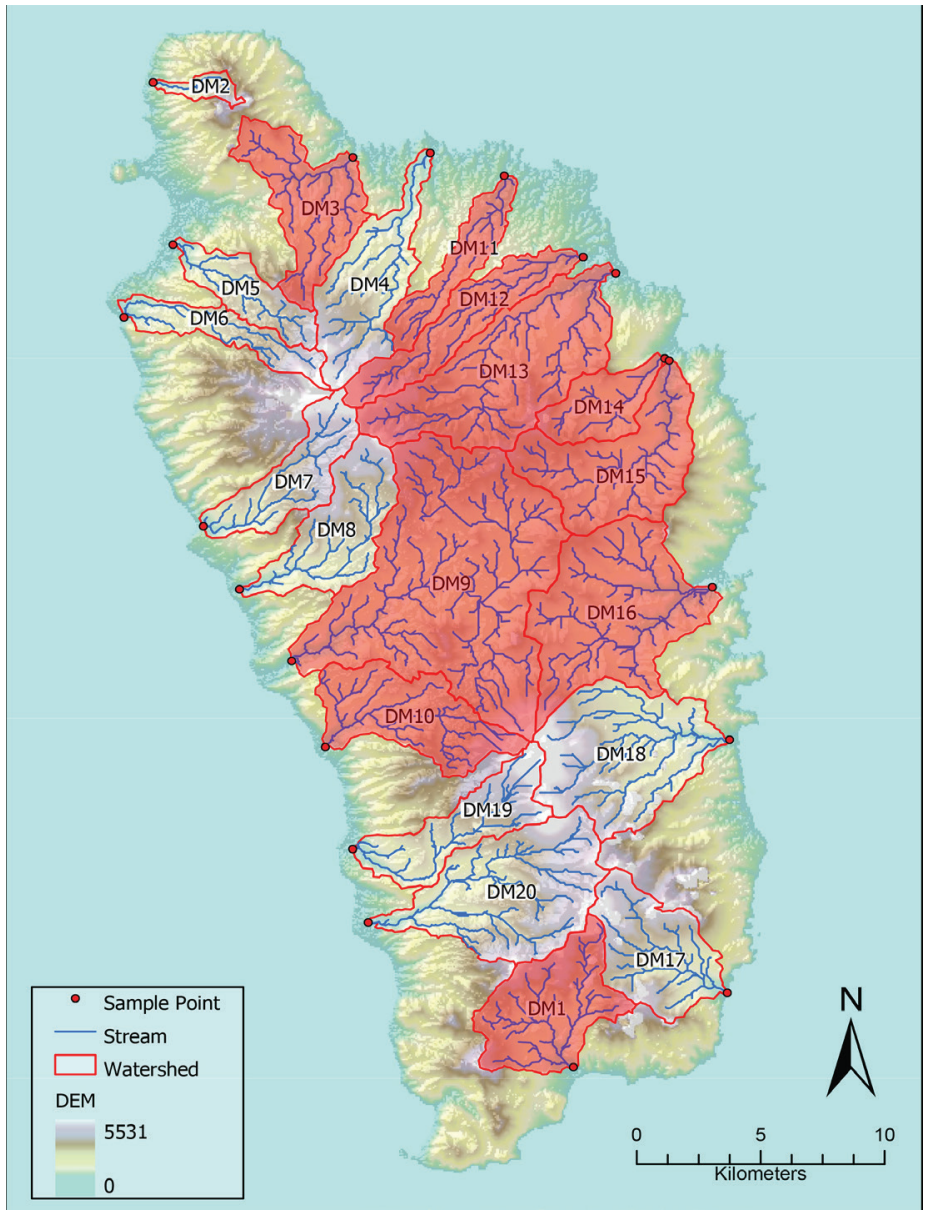

Figure 1. A map of Dominica displaying boundaries (outlined in red) and sampling locations (red points) of 20 watersheds with areas greater than $10 \mathrm{~km}^{2}$. Watersheds with higher than average iron ratios are highlighted in red. The watershed map was created by Kira Tomenchok.

\section{Radioactive isotope analysis}

We followed a procedure similar to Singleton et al. (2017): we prepared samples by leaching them in hydrochloric acid, then used a gamma counter to analyze the amounts of ${ }^{7} \mathrm{Be},{ }^{137} \mathrm{Cs}$, and ${ }^{210} \mathrm{~Pb}$. We were only able to analyze 12 samples so far.

\section{Satellite image analysis}

I used Adobe Photoshop to compile composite pictures of Dominica before Tropical Storm Erika hit the island in August 2015. I stitched satellite images together in order to reduce cloud interference, then made a visual inspection to identify possible landslides. These landslides were marked in a new layer in Photoshop (Fig. 2). We were able to use imagery from the World Bank taken between Tropical Storm Erika and 

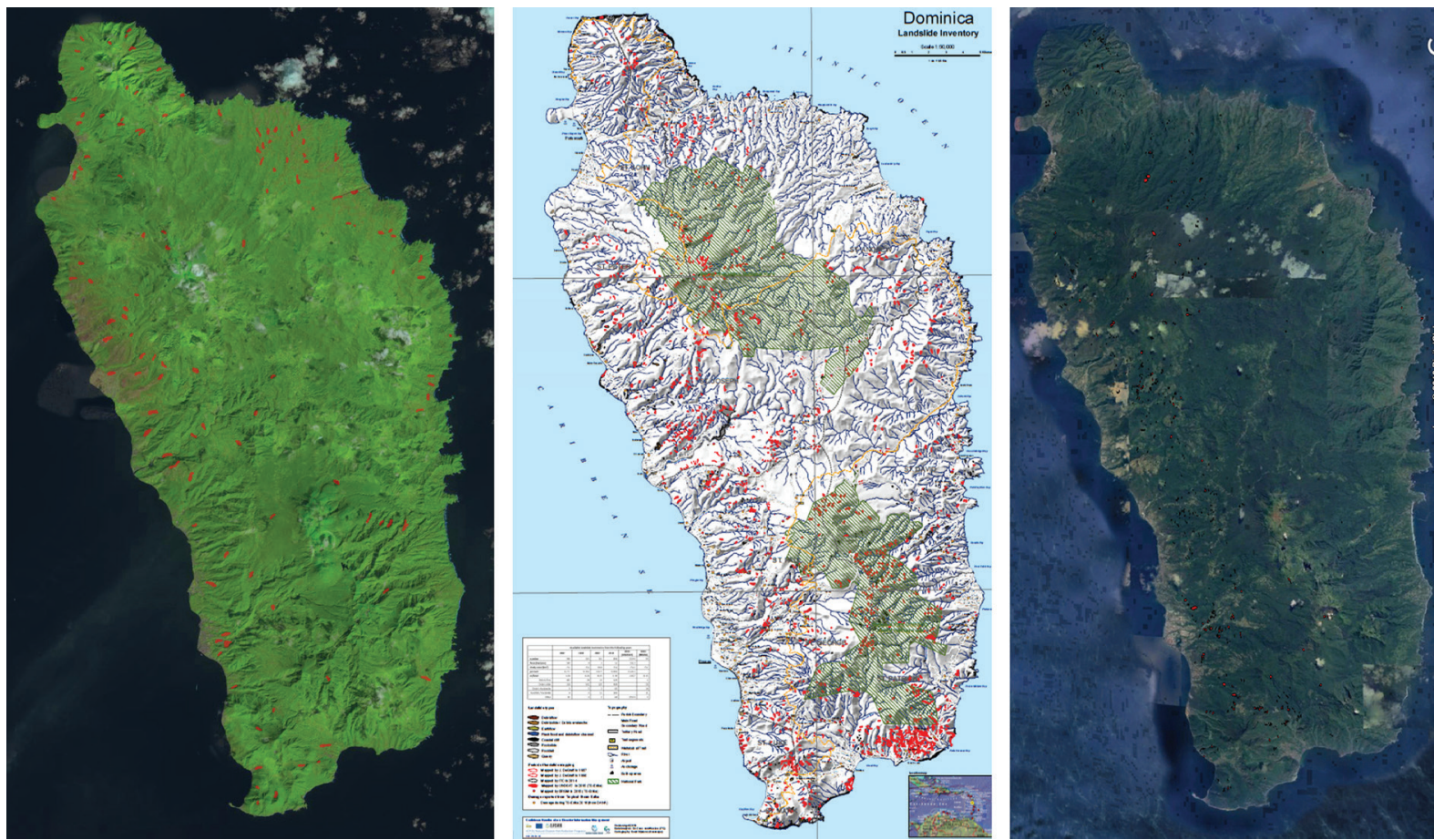

Figure 2. On the left, a stitched satellite image of Dominica using raw images from a range of dates between 2010 and 2015 (before Tropical Storm Erika) in order to reduce cloud cover in the stitched image, with disturbed land areas overlain in red. In the center, a map of landslides present after Tropical Storm Erika, from Van Westen (2016). On the right, satellite imagery from Google Earth overlain with landslides which Marcus Hill identified in post-Hurricane Maria (September 2017) imagery.

Hurricane Maria. The post-Hurricane Maria landslides were mapped by Marcus Hill using ArcGIS.

\section{RESULTS}

\section{XRD analysis}

All of the samples returned very similar results, with peaks at $2 \theta \approx 44.7^{\circ}, 65.1^{\circ}, 78.2^{\circ}, 38.4^{\circ}$, and $22.0^{\circ}$, in decreasing order of intensity (Fig. 3). We attempted to utilize an online mineral database to match the peaks with known minerals, but were unable to find matches within the known mineral families present on the island. The closest mineral matches based on the peaks were minerals such as periclase, heterosite, and triphylite, which are unlikely to exist in this geologic setting.

\section{XRF analysis}

We found that the coarse samples and fine samples from the same location often differed in their relative proportions of various elements, including iron to silicon and iron to aluminum (Table 1). For example, the coarse sample from location DM-01 has a relatively high proportion of iron in the fine sample and a relatively low proportion of iron in the coarse sample.

We also found some patterns within the fine and coarse sediment groups. There is a group of fine-grained samples, numbers DM-01, 03, and 09 - 16, with higher than average iron:silicon and iron:aluminum ratios (with the exception of the iron:aluminum ratio in DM10). These watersheds are for the most part located in the central and northeast part of the island (Fig. 1).

\section{Radioactive isotope analysis}

None of the samples analyzed contained detectable amounts of ${ }^{137} \mathrm{Cs}$, and only DM-15AL contained a detectable amount of ${ }^{7} \mathrm{Be}$. However, all of the samples contained at least some ${ }^{210} \mathrm{~Pb}$ (Fig. 4).

\section{Satellite image analysis}

In the post-Maria landslide map, we were able to detect more and smaller landslides than in the pre-Erika map, but this was because we used satellite imagery from different sources for the two maps and the postMaria satellite imagery was much higher resolution 


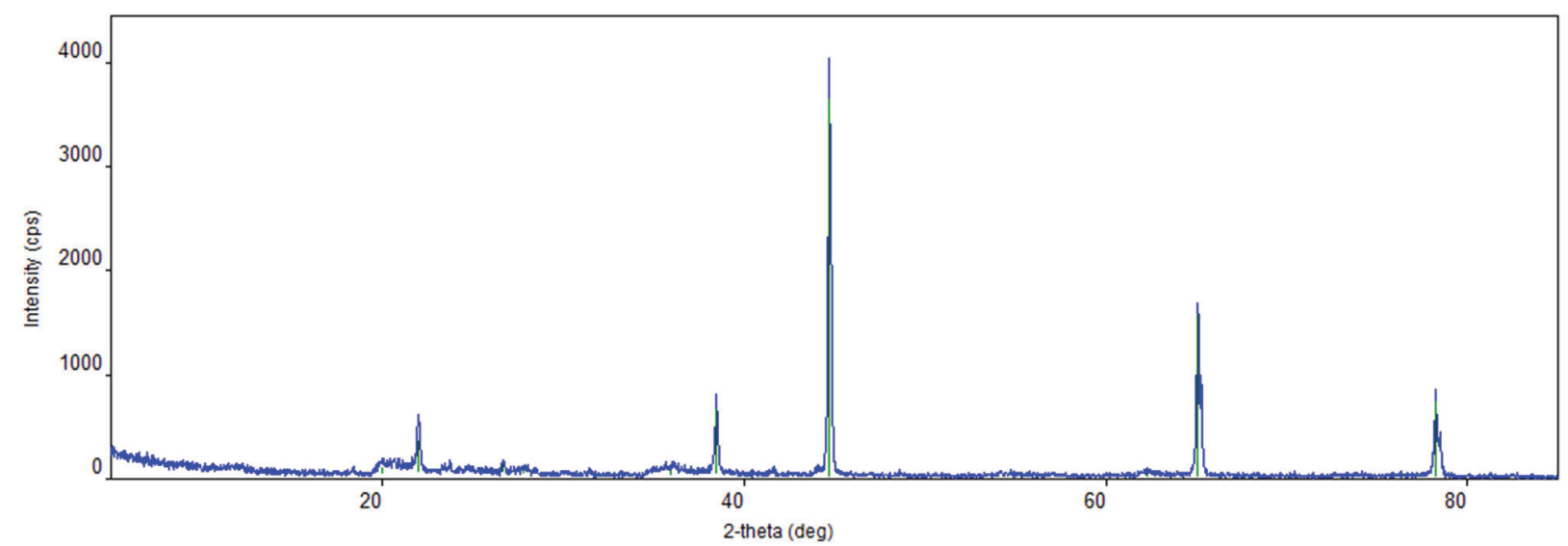

Figure 3. A plot of intensity (cps) vs $2 \theta$ (deg) for sample DM-11. This sample's plot is representative of those obtained for other samples.

than the pre-Erika imagery. In all maps, we found more landslides on the western half of the island than on the eastern half, with the exception of a cluster of landslides in the southeast in the post-Erika map. It appears that landslides are generally reactivated or occur in similar locations following storm events, but the varying resolutions of the three maps make it difficult to make accurate comparisons.

Table 1. Cation ratios in sediment samples from Dominica

\begin{tabular}{|c|c|c|c|c|c|c|}
\hline & Fine & & & Coarse & & \\
\hline Sample number & Fe:Si & Fe:Al & Al:Mg & $\mathrm{Fe}: \mathrm{Si}$ & Fe:Al & Al:Mg \\
\hline 1 & 15.62 & 102.15 & 20.29 & 8.39 & 56.97 & 22.89 \\
\hline 2 & 8.16 & 52.77 & 23.39 & 12.06 & 82.47 & 17.34 \\
\hline 3 & 13.03 & 72.41 & 31.81 & 16.93 & 103.62 & 25.32 \\
\hline 4 & 9.04 & 55.04 & 28.82 & 13.24 & 93.19 & 15.50 \\
\hline 5 & 11.15 & 66.25 & 23.42 & 9.35 & 61.84 & 20.02 \\
\hline 6 & 9.29 & 58.19 & 25.43 & 11.53 & 81.59 & 19.75 \\
\hline 7 & 11.08 & 69.92 & 25.05 & 13.65 & 88.28 & 17.92 \\
\hline 8 & 10.66 & 64.15 & 27.17 & 16.99 & 132.33 & 11.84 \\
\hline 9 & 13.25 & 79.49 & 24.29 & 11.77 & 67.82 & 18.89 \\
\hline 10 & 12.31 & 62.47 & 22.82 & 10.25 & 60.37 & 23.12 \\
\hline 11 & 15.05 & 69.53 & 19.13 & 24.20 & 117.27 & 21.83 \\
\hline 12 & 15.30 & 81.61 & 28.11 & 9.89 & 61.25 & 19.85 \\
\hline 13 & 14.18 & 69.55 & 33.28 & 10.19 & 73.77 & 17.59 \\
\hline 14 & 18.56 & 78.72 & 20.08 & 15.04 & 74.84 & 25.98 \\
\hline 15 & 17.77 & 78.17 & 19.62 & 15.91 & 68.05 & 24.64 \\
\hline 16 & 15.96 & 72.07 & 25.38 & 11.41 & 54.87 & 20.47 \\
\hline 17 & 8.77 & 49.88 & 23.73 & 9.22 & 62.45 & 20.02 \\
\hline 18 & 9.95 & 55.21 & 26.47 & 12.54 & 83.82 & 17.38 \\
\hline 19 & 7.88 & 47.89 & 23.38 & 10.32 & 68.66 & 16.19 \\
\hline 20 & 8.03 & 51.00 & 24.87 & 6.07 & 39.59 & 24.19 \\
\hline
\end{tabular}

Note: Cells highlighted in orange are cation ratios greater than the average value for samples the same grain size.

\section{DISCUSSION}

Although our XRD analysis does not allow us to differentiate which minerals are present in our samples, we are able to conclude that all of our samples have a similar mineralogy (Fig. 3). Considering that Dominica is an island where many parent rocks have similar mineral assemblages which then go through a clay mineral weathering sequence (Frey 2016), we are able to conclude that the watersheds which we studied undergo processes which produce similarly weathered sediments.

There are some samples where, based on our XRF data, the fine and coarse sediment vary in composition. Not all displayed the same pattern of differences though; some sample locations had higher iron-tosilicon and iron-to-aluminum ratios in the fine portion, while others had a larger ratio in the coarse portion (Table 1). This lack of systematic difference indicates that there are not specific elements that are preferentially weathered across the island. In addition, there are more spatial patterns in the fine-grained sediments. Specifically, fine samples from adjacent watersheds often had similar iron:silicon, iron:aluminum, and magnesium:aluminum ratios, while these ratios varied more widely in coarse samples from adjacent watersheds (Fig. 1). The fine-grained sediments could therefore serve as a more sensitive indicator for weathering than the coarse-grained sediments.

The lack of ${ }^{137} \mathrm{Cs}$ in these samples indicates that there has been deep erosion since the time of ${ }^{137} \mathrm{Cs}$ deposition, as modern sediment sources are deeper than 


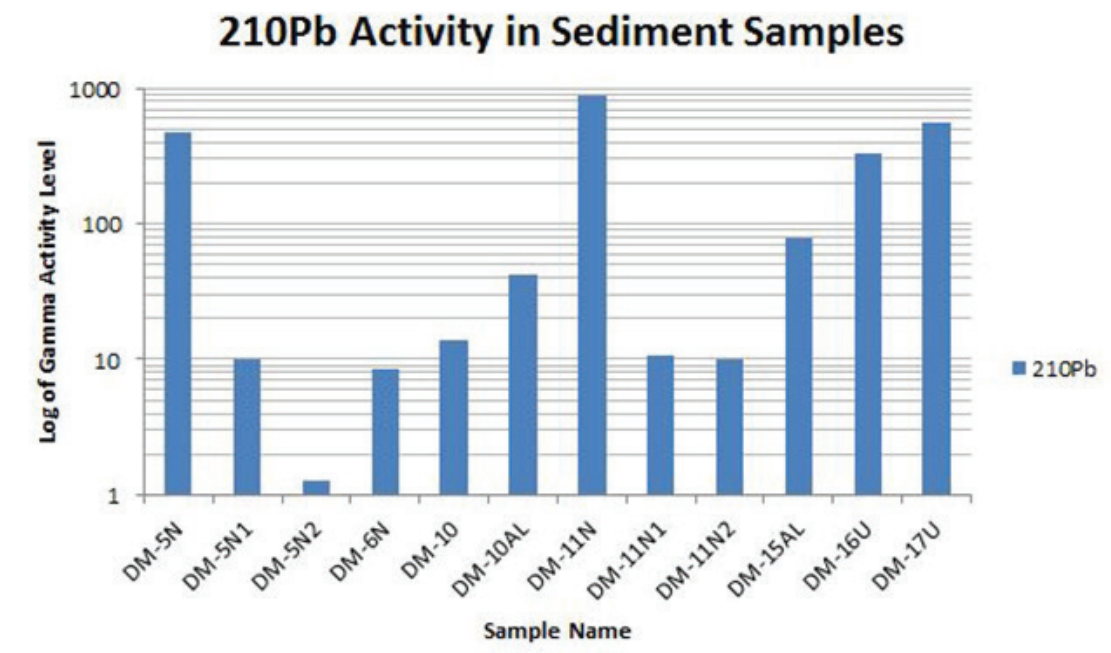

Figure 4. A logarithmic plot depicting the amount of ${ }^{210} \mathrm{~Pb}$ detected in various sediment samples.

where ${ }^{137} \mathrm{Cs}$ would have been deposited (Singleton et al., 2017). This conclusion is also supported by the lack of ${ }^{7} \mathrm{Be}$. The presence of ${ }^{210} \mathrm{~Pb}$ in all samples indicates that more recent erosion has been somewhat slower and sources some surface material, as the sediments must have been exposed on the surface for at least some time in order to allow ${ }^{210} \mathrm{~Pb}$ to accumulate (Singleton et al., 2017).

Our satellite landslide maps are consistent with what the Van Westen (2016) report predicts. This report highlighted the northwest and south central mountains as areas where there was a relatively higher risk of "soil slides," and we found the majority of landslides were in these areas (Fig. 2). The pre-Erika map includes a cluster of large landslides in the northeast coastal plain, where there is a low risk of soil slides in the Van Westen (2016) report and only a few small ones were found in the post-Maria images; this cluster is most likely the result of mislabeling land that was disturbed by something other than a landslide (such as human activities). There does not appear to be any correlation between the landslides and our XRF data.

\section{CONCLUSIONS}

Based on XRD analysis, we found that there are similar erosive processes are occurring throughout the different watersheds we analyzed. We were unable to differentiate different watersheds based on the XRD results. We also conclude that fine-grained sediments serve as better markers for weathering of different ele- ments based on their higher spatial correlation in XRF tests. This could be applied to continued research by prioritizing fine-grained sediment collection if resources and time are severely limited.

We found that landslides are relatively common across the island, and that post-storm landslides generally occurred in areas where they had occurred before.

The importance of landslides as an erosive factor is partly confirmed by the fallout radionuclide data; there has to have been enough erosion in the recent past to remove ${ }^{137} \mathrm{Cs}$ deposits, and this erosion could have been achieved through landslides. Landslide frequency is also emphasized in our satellite image mapping. They are present across the island in images from three different points in time, sometimes in large clusters. Post-storm landslide locations can be predicted based on past landslides, but they can also be predicted based on factors such as slope steepness and soil type (Van Westen, 2016). In their report, Van Westen discusses how there were many individual landslides following Hurricane Erika which occurred in areas that had been predicted as low or moderate risk and notes this as an area for future improvement in landslide prediction. Van Westen (2016) discusses how some of the data sets they used were low resolution, and this discussion coupled with the varying resolutions of the satellite imagery we acquired emphasize the need for continued, and detailed, research in the Caribbean. Some islands might be relatively well-studied, but each one is different and requires its 
own data collection in order to allow scientists to accurately create and compare hazard maps. Failing to thoroughly study and evaluate all the risks inherent to any one island could lead to continued loss of life and property from natural disasters such as landslides and volcanic eruptions, which is why it is so important to continue researching and collecting data on Dominica and throughout the Caribbean.

\section{ACKNOWLEDGEMENTS}

This material is based upon work supported by the Keck Geology Consortium and the National Science Foundation under Grant No. 1659322 and made possible by a research permit from Dominica's Ministry of Forestry. I would also like to thank Amanda Schmidt for all her guidance and encouragement throughout this entire process, and the rest of Team Geomorph for being excellent collaborators and partners.

\section{REFERENCES}

Alcántara-Ayala, I., 2002, Geomorphology, natural hazards, vulnerability and prevention of natural disasters in developing countries: Geomorphology, v. 47, p. 107-124.

Campbell, M. K., Bower, J. A., Schmidt, A. H., Neilson, T. B., Sosa-Gonzalez, V., and Bierman, P. R., 2015, Fallout radionuclides in soil profiles and history of land use in Yunnan Province, China: Geological Society of America Abstracts with Programs, v. 47, no. 7, p. 515.

Frey, H., 2016, Dominica: The sleeping giant in the Caribbean: Franklin \& Marshall Scientist 2016, p. 3-37.

Gonzalez, V. S., Schmidt, A. H., Bierman, P. R., and Rood, D. H., 2017, Spatial and temporal replicability of meteoric and in situ ${ }^{10} \mathrm{Be}$ concentrations in fluvial sediment: Earth Surface Processes and Landforms, v. 42, p. 2570-2584.

Hancock, G. R., Coulthard, T. J., and Lowry, J. B. C., 2016, Predicting uncertainty in sediment transport and landscape evolution-the influence of initial surface conditions: Computers \& Geosciences, v. 90, P.B., p. 117-130.

Lindsay, J. M., Smith, A. L., Roobol, M. J., and Stasiuk, M. V., 2005, Dominica: Volcanic Hazard Atlas of the Lesser Antilles, p. 1-48.
Portenga, E. W., Bierman, P. R., Rizzo, D. M., 2009, A global summary and analysis of exposed bedrock erosion rates estimated using in situ ${ }^{10} \mathrm{Be}$ : Geological Society of America Abstracts with Programs, v. 41, no. 7, p. 619.

Singleton, A. S., Schmidt, A. H., Bierman, P. R., Hood, D. H., Neilson, T. B., Greene, E. S., Bower, J. A., and Perdrial, N., 2017, Effects of grain size, mineralogy, and acid-extractable grain coatings on the distribution of the fallout radionuclides ${ }^{7} \mathrm{Be},{ }^{10} \mathrm{Be},{ }^{137} \mathrm{Cs}$, and ${ }^{210} \mathrm{~Pb}$ in river sediment: Geochimica et Cosmochimica Acta, v. 197, p. 71-86.

Van Westen, C. J., 2016, National scale landslide susceptibility assessment for Dominica, in CHARIM Caribbean Handbook on Risk Information Management: World Bank GFDRR.

Vijith, H., Suma, M., Rekha, V. B., Shiju, C., and Rejith, P. G., 2011, An assessment of soil erosion probability and erosion rates in a tropical mountainous watershed using remote sensing and GIS: Arabian Journal of Geosciences, v. 5, p. 797-805. 